\section{Biopiracy rules hinder conservation efforts}

SIR - The summits of the neotropical Guayana Highlands in Venezuela have a unique biodiversity that is under serious threat because of habitat loss resulting from climate warming. Although conservation studies are urgently needed, these are blocked by official bodies that will not grant permits for fieldwork in the region.

The bureaucratic process starts with the Venezuelan government's agency for science and technology, FONACIT, and involves a network of different organizations controlled by the ministry of the environment. These include the national tepui (table-mountain) commission, the biodiversity office, the office of indigenous affairs and the national institute of parks.

We have been involved since July 2005 in an international conservation project, funded by the Spanish BBVA Foundation, on the Guayana Highlands flora, in collaboration with several Venezuelan universities, research institutes and other organizations. It took us two years to obtain permits from FONACIT and for sample collection to be authorized. For unspecified reasons, the permits do not allow genetic studies, so molecular phylogenetic analysis is impossible. We are still trying to obtain approval from the office of indigenous affairs, but the people are reluctant to comply: they consider themselves owners of the summits, which are sacred lands to them.

The lengthy bureaucratic procedures have prevented scientific fieldwork in the Guayana Highlands for almost twenty years, when permissions to visit the summits for any purpose were suspended to avoid human disturbance and biopiracy (see below, 'Biopiracy: conservationists have to rebuild lost trust' Nature 453, 26; 2008). It is to be hoped that the situation may be reversed before it is too late to undertake suitable conservation strategies.

Valentí Rulı ${ }^{\star}$, Teresa Vegas-Vilarrúbiał *Department of Animal Biology, Plant Biology and Ecology, Autonomous University of Barcelona, Faculty of Biosciences C1-339, Bellaterra, 08193 Barcelona, Spain

$\uparrow$ Department of Ecology, University of Barcelona, Faculty of Biology, Av. Diagonal 645, 08028 Barcelona, Spain

\section{Biopiracy: conservationists have to rebuild lost trust}

SIR - Working just south of Valentí Rull and Teresa Vegas-Vilarrúbia, we share the frustrations they describe on this page over obtaining permits - even though we only collect observations ('Biopiracy rules hinder conservation work' Nature 453, 26; 2008).

However, we disagree with the implications they draw for conservation.

Biopiracy is a matter of deep concern for indigenous peoples, who all too often have had their heritage abused. Practical conservation actions must adapt accordingly.

In 2001-02, a Japanese company controversially registered the common name of the fruit 'cupuaçu' (Theobroma grandiflorum) as a trademark. This aroused a great deal of alarm.

Brazil's national justice secretary, Romeu Tuma, is now asking Congress to consider a bill requiring foreigners - individuals, religious groups and environmentalists to have a permit before visiting the Amazon (see http://tinyurl.com/6kygfm).

Contact with indigenous peoples is also contentious for other reasons. Whatever the merits of scientific exploration, indigenous peoples need to know how to evaluate researchers' requests and find out what is in it for them. After all, outside contact sometimes means massive cultural disruption - as with oil exploration in the western Amazon.

Conservation professionals can do much to improve the situation. They can start by acknowledging the rights of indigenous peoples, as recognized by Article 31 of the United Nations Declaration on the Rights of Indigenous Peoples (see http://tinyurl. com/5okbd7). Then, they can investigate indigenous people's needs through personal contact.

Practical actions that can be undertaken by researchers include providing Global Positioning System units and training in how to use them so that peoples can define their territories, helping to market traditional handicrafts or ecotourism, and building schools. Free, informed consent, obtained in advance through the proper channels, can ensure meaningful participation of indigenous peoples in project design and implementation. This should also minimize confrontations and the delays they cause.

Such actions are not a quid pro quo, but arise from a sense of justice. They can provide an important framework of trust for the ultimate conservation question: will indigenous groups manage their own lands, their own biodiversity, in sustainable ways?

Scientific needs are one small step on the way to that dialogue. We should not miss that step by focusing only on completing research projects.

Mariana M. Vale ${ }^{\star}$, Maria Alice Alves*, Stuart L. Pimm'

*Departamento de Ecologia, Universidade do Estado do Rio de Janeiro,

Rua São Francisco Xavier 524, Maracanã,

Rio de Janeiro 20550-011, Brazil

$\uparrow$ Nicholas School of the Environment,

Duke University, Box 90328, Durham,

North Carolina 27708-0328, USA

\section{Spain should implement a model that's known to work}

SIR - Your Editorial about the current state of Spanish science (Nature 451, 1029; 2008) suggests that 'A new Silver Age' is possible. Although Spain's research investment, at 1.1\% of gross domestic product, is still below the European average (1.8\%), the recent boost in the science budget has funded plans such as the Ramón y Cajal programme, intended to recover young scientists from abroad, and the creation of independent research institutes. But unless there are radical policy changes, the increased funding will not be sufficient to reduce the science chasm between Spain and other countries.

Blatant 'inbreeding' practices still thrive. Some $90 \%$ of Spanish scientists continue to occupy positions at the institutions where they obtained their PhDs, a situation that hinders the mobility and exchange of ideas that underpin strong science (see Nature 410, 14; 2001; Nature 411, 132; 2001). The Popular (conservative) Party, which governed from 1996 to 2004, brought in a national committee to replace the local committees that had previously been responsible for appointments. Although this maintained high standards for selection, it has failed to reduce academic endogamy. And although vacancies at most institutions are now publicized, this usually happens only after an in-house candidate has been unofficially chosen for the job.

A proposal by the current socialist government allows national evaluation of a candidate exclusively on the grounds of a detailed CV. However, that will still not solve the problem, as universities and research centres - which retain control of the final selection process - continue to favour their own candidates. Many of the Spanish regional governments have set up local evaluation agencies, often with different criteria: a positive report is mandatory when applying for a position in that particular region.

An even more flagrant practice favours candidates who are fluent in the local language, in addition to Castilian, irrespective of their scientific merits. This discriminates against non-local and foreign scientists trying to build a career in Spain. This is common practice and is in violation of the European Charter for Researchers (http://tinyurl.com/42zbdg).

Spanish policy-makers should stop reinventing the wheel in every four-year term. Instead, they should implement models that have worked for decades in countries with a long-standing tradition in science, such as the Max Planck institutes in Germany or the Medical Research Council in the United Kingdom.

Increased funding must be accompanied 